\title{
The Annual costs of treating genital warts in the Public Healthcare Sector in Peru
}

\author{
Enrique M Saldarriaga ${ }^{1,2}$, Cesar P. Cárcamo ${ }^{1}$, Joseph B. Babigumira ${ }^{2,3}$ and Patricia J. García ${ }^{1,3^{*}}$
}

\begin{abstract}
Objectives: To estimate the cost of six different techniques used to treat Genital Warts and the annual average cost of treating a typical GW patient in Peru. To estimate the annual economic burden diagnosing and treating GW in the Peruvian public healthcare system.

Methods: We developed a prevalence-based, cost-of-illness study from the provider's perspective, the healthcare facilities under the purview of Peruvian Ministry of Health. We used an activity-based costing approach. We conducted primary data collection in three regions in Peru and supplemented it with governmental data. Uncertainty of the costing estimates was assessed via Monte Carlo simulations. We estimated the average cost and associated confidence intervals for six treatment options - three topical and three surgical - and the overall cost per patient.
\end{abstract}

Results: The average treatment cost per patient was 59.9USD ( $95 \% \mathrm{Cl} 45.5,77.6)$. Given a population of 18.4 million adults between 18 and 60 years of age and a GW prevalence of $2.28 \%$, the annual cost of treating GW was 25.1 million USD (uncertainty interval 16.9, 36.6).

Conclusions: This study provides the first quantification of the economic burden of treating genital warts in Peru and one of the few in Latin America. The costing data did not include other healthcare providers or out-of-pocket expenditures, and hence we present a conservative estimate of the COI of GW in Peru. Our findings bring attention to the financial burden of treating GW, a vaccine-preventable disease.

Keywords: Genital warts, Cost-of-illness, Micro-costing, Peru

\section{Introduction}

Genital warts $(\mathrm{GW})$ are the most common viral sexually transmitted infection (STI) globally [1]. They are manifestations of anogenital human papillomavirus (HPV). In particular, HPV-subtypes 6 and 11 are causative agents of the disease [2-4]. GW present as external skin lesions of the vulva, penis, anus and scrotum, and mucosal lesions of the vagina, cervix, and urethra [5].

\footnotetext{
*Correspondence: patricia.garcia@upch.pe

'Epidemiology, STD and HIV Unit, School of Public Health and Administration, Universidad Peruana Cayetano Heredia, Lima, Peru ${ }^{3}$ Department of Global Health, School of Public Health, University of Washington, Seattle, Washington, USA

Full list of author information is available at the end of the article
}

Data related to the incidence and prevalence of GW varied significantly within countries [1]. To date, the only study that has estimated the prevalence of $\mathrm{GW}$ in Peru was conducted by García et al [6]. The authors conducted a survey among 100 physicians from public facilities to quantify the frequency of GW cases detected, as well as diagnosis practices and patients' characteristics. The prevalence of GW among all Peruvian adults between 18 and 60 years of age was estimated in $2.28 \%$ (95\% Confidence Interval (CI) 2.02, 2.56). Among males the prevalence was $5.25 \%(95 \% \mathrm{CI} 4.46,6.13)$ and among females was $1.35 \%(95 \% \mathrm{CI} 1.13,1.61)$ [6].

While reports suggest that most GW cases are asymptomatic, location, size, and number of the lesions usually determines the presence of symptoms, including pain,

(c) The Author(s). 2021 Open Access This article is licensed under a Creative Commons Attribution 4.0 International License, which permits use, sharing, adaptation, distribution and reproduction in any medium or format, as long as you give appropriate credit to the original author(s) and the source, provide a link to the Creative Commons licence, and indicate if changes were made. The images or other third party material in this article are included in the article's Creative Commons licence, unless indicated otherwise in a credit line to the material. If material is not included in the article's Creative Commons licence and your intended use is not permitted by statutory regulation or exceeds the permitted use, you will need to obtain permission directly from the copyright holder. To view a copy of this licence, visit http://creativecommons.org/licenses/by/4.0/ The Creative Commons Public Domain Dedication waiver (http://creativecommons.org/publicdomain/zero/1.0/) applies to the data made available in this article, unless otherwise stated in a credit line to the data. 
pruritus, and bleeding [7, 8]. While $\mathrm{GW}$ can be selflimiting, several patients require topical treatment or surgical procedures. The choice of treatment usually depends on the clinical assessment of the lesion, cost of the procedure, patients' characteristics, and physicians' preferences [9]. Although the treatment of GWs has been associated to increased individual and healthcare costs [10-12], only few countries in Latin America have studies assessing the costs and the economic burden of GW in the population [13-15]; Peru is not one of them.

Peru has a mixed healthcare system with public and private providers and insurers. While most of the private institutions are specialized in either service, public institutions are upstream integrated and therefore offer insurance and healthcare services [16]. The most important provider and insurer is the Ministry of Health $(\mathrm{MoH})$ through the comprehensive health insurance (SIS by its acronym in Spanish - Seguro Integral de Salud) that covers $44.4 \%$ of the population [17]. This structure has two implications. First, access to care its restricted by insurance membership; e.g., only holders of the SIS can be treated by the $\mathrm{MoH}$. Second, most institutions are both a health services providers and payers. Therefore, the $\mathrm{MoH}$, as the most important provider in the country, is expected to bear the biggest proportion of the costs associated to diagnose and treat $\mathrm{GW}$ in the country.

The $\mathrm{MoH}$ provides vaccination free of charge to all Peruvian citizens for all vaccines in the national immunization scheme. Peru introduced the bivalent HPV vaccine, that confers protection against the highrisk subtypes, 16 and 18 [18], for the first time in 2011 for girls from 9 to 14 years old. Just in 2016 the national vaccination scheme changed to the quadrivalent vaccine that also protects against the HPV-types 6 and 11 [19].

The objective of the study was to address the population-level costs of GW diagnosis and treatment, to present the economic burden of a disease, that could be prevented with a gender-neutral vaccine.

\section{Methods}

\section{Study design}

We conducted a cost-of-illness (COI) study aiming to estimate the total healthcare expenditures used to diagnose and treat people with GW. We used an activitybased (micro-costing) technique to estimate the cost of diagnosis and each treatment option from the provider's perspective, the facilities under the purview of the Peruvian Ministry of Health $(\mathrm{MoH})$.

The micro-costing technique decompounds each service (i.e., diagnosis and treatment options) into the inputs and quantity required to provide it. We then find the best price for each input and multiply it by the amount needed. The sum of all inputs provides an estimate of the cost per service. Since we used the provider's perspective for the costing analysis, only direct medical costs (e.g. drugs, materials, equipment, and physicians' and nurses' wages) were included [20].

Since we used a prevalence-based approach, the COI is determined by the product of the prevalent cases and the average treatment cost $[21,22]$. The prevalence was obtained from a previous study conducted by Garcia et al [6]. In the following sections we describe how each treatment's technique cost was estimated, as well as how we arrived at the overall average treatment cost.

\section{Materials}

We leverage the results found by Garcia et al [6] regarding the prevalence of GW, providers' preferences for GW diagnostic methods, and distribution of cases across gender and type of case. Cases were categorized by physicians into "new" - no history of previous diagnosis, "resistant" - episode lasting longer than six months despite treatment, and "recurrent" - new case that appears within 12 months of previous episode. That study included physicians from six specialties: primary care physicians (including general practitioners and family medicine doctors), gynecologists, urologists, dermatologists, and infectious disease specialists.

To identify resource use for a typical visit, we developed a flow map of key activities completed during a visit (Fig. 1). Then we conducted a review of national guidelines [23] to identify the materials used in each activity according to protocol. Additionally, we updated and improve this information with eight in-depth interviews with physicians that participated in Garcia's study [6]. These interviews were used to get further information about treatment practices, preferences for specific treatments, materials and equipment used in each procedure, duration of each procedure, and validation of the treatment algorithms.

In 2016, we conducted primary costing-data collection in Lima (coastal city and capital of Peru), Ayacucho (Andean region), and Iquitos (Jungle). The selection of sites was purposive. Each site represents a major region in Peru and therefore it allowed us to collect the most heterogeneous costing data, resources utilization (i.e., quantity of the resources used), and clinical practices to create robust estimates. In addition, it is coherent with the study design of Garcia, et al., so it preserves internal consistency.

We interviewed a total of nine administrative and logistics officers that provided the unitary costs of all drugs, materials, medical supplies, and equipment used for each treatment option. From each interview we obtained purchasing data that contained, for each input, volume of purchase and price paid, or directly unitary cost. The unit cost of disposable inputs (e.g., cotton, 


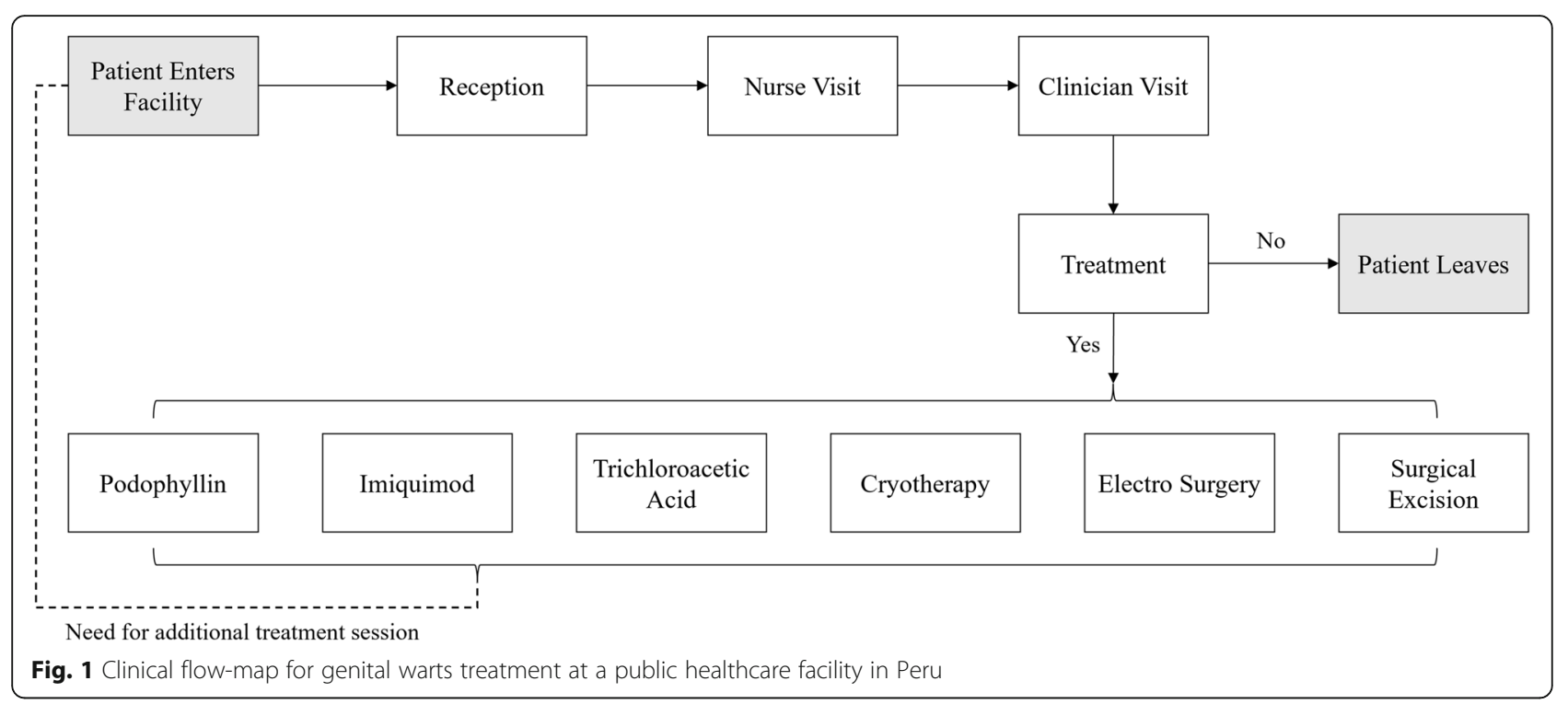

needles) relies on the assumption that in every session the entire input is used (i.e., no partition for reuse). To estimate the unitary cost of durable inputs (e.g., equipment, medical instruments) we used the depreciation method [24]. From the interviews with administrative officers, we obtained the total cost of the good, enquire about the rotation period (e.g., how often an equipment is changed, or infrastructure renovated), from which we obtained the useful life, which we finally used to estimate the depreciation cost per minute. Thus, the unitary costs were in the same unit as the duration of each activity.

Regarding human resources, we used the opportunity cost of the paid-time of the healthcare workers $(\mathrm{HCW})$ [25]. We obtained salary data from the National Registry of Healthcare Personnel (INFORHUS) from the $\mathrm{MoH}$ to improve the precision of the wage estimates. We used this information to estimate the cost per minute per type of HCW and the estimated time per activity reported by the interviewed physicians to calculate the attributable costs to each treatment. We obtained the costs for six key HCW: receptionist, file staff, cashier, nurse, physician, pharmacist, whose regular activities are fairly differentiated and therefore we minimized the risk of overlapping. We used the information from the validate flow map (Fig. 1) to match activities with the HCW that most likely will perform them.

From this information we estimated mean and standard deviation (SD) of the unitary cost of each input. In all cases outliers were excluded if a value was a at least 3 times bigger than its peers. While a few inputs have a large variability (see supplemental material sheet "Costing data") we decided in favor of the mean, instead of quantile-based metrics such as the median, because it easier to communicate, it allows for a more straightforward implementation of the probability-based sensitivity analysis, and the impact of each individual input is too small to bias the results. The SD captures the variability of the unitary cost given regional differences, purchase preferences, and others.

\section{Analysis}

First, we estimated the cost per session for a diagnosis appointment and each treatment technique. This is the sum-product of the resources' amount needed to provide a service and its unitary costs. To account for the variability of the unitary costs we performed a Monte Carlo simulation [26]. We used a random number generator to obtain 1,000 estimates of each unitary cost based on a gamma distribution - the recommended distribution for cost data [27] - parameterized using the mean and standard deviation. Each draw from the distribution for all parameters is a simulation of the costing data, and therefore we obtained 1,000 simulations of the data. We estimated the final average costs 1,000 times and we were able to obtain the $2.5 \%$ and $97.5 \%$ percentiles of the distribution. Some parameters had no sample variability when only one source of information was obtained. In those cases, we assumed a SD of 1e-9 to conduct the simulation. Following the same process, we decomposed the cost per session into categories of costs: human resources, infrastructure, equipment, drugs, medical instruments, disposable materials, and public services. We present both the cost per session and the cost per cost category.

Second, in our study, the GW are compartmentalized by the combination of four groups given by the biological gender of the patient ( 2 categories), the type of case ( 3 categories), the physician's specialty ( 5 categories), and treatment technique received (6 categories), 
resulting in 180 possible combinations. Each combination is called a compartment. The probability across compartments is not homogeneous and hence we sought to find the specific distribution of cases for each one. We used the information reported by Garcia et al [6] to estimate the distribution of cases given the combination of patient's gender, type of case, and physicians' specialty. The probability of no receiving treatment care once the warts have been detected vary across specialties but in all cases is negligible (see Garcia et al. [6]). The in-depth interviews provided us with the probability of choosing each treatment by physician specialty. We use these probabilities to estimate the final probability of each compartment. We report all the probabilities used for this analysis.

Third, we estimated the annual cost of treatment per patient as the product of (a) the cost of each session plus the cost of the diagnosis appointment, (b) the number of times the treatment was applied to each patient, dependent upon patients' characteristics, type of case (new, recurrent, or resistant), and physicians' preferences, and (c) the number of episodes within a year for recurrent cases. Thus, we obtained the annual cost per patient in each compartment. We report the average number of sessions per treatment, the overall number of episodes in recurrent cases by gender, and the final cost by treatment.

Fourth, we obtained an estimate of the average cost of diagnosing and treating a typical patient in one year as the sum-product of the annual cost per patient in each compartment and the associated compartment's probability. Hence, this corresponds to a weighted average, where the weights are the probabilities of observing each combination of patient' characteristics and physicians' preferences. Given the distribution estimated for the cost per session (first point), we can estimate $95 \%$ confidence interval for the annual cost of treating a typical case of GW.

Fifth, the COI of diagnosis and treating GW, is the product of the average treatment cost and the prevalence of GW. We calculate the point-estimate and range of feasible values of the COI. The point-estimate is the product of the mean values of prevalence and the average treatment costs. The lower bound is the product of the $95 \% \mathrm{CI}$ 's lower-bound for both the prevalence of genital warts and the cost of treatment; conversely, the upper-bound uses the upper-bound of the $95 \% \mathrm{CI}$ for both metrics.

Finally, the number of GW cases is based on the most recent estimation of population by age and gender, in 2017 the population of Peruvians between 18 and 60 years old was 18.4 million, 9.3 of them are males and 9.1 females [28].

All the costing data was collected in 2016 Peruvian Soles (PEN), but the results are expressed in 2019 US
Dollars (USD) using a fixed conservative exchange rate of 3.3 PEN for each USD, and a yearly inflation of $2.5 \%$.

\section{Results}

The most used techniques to treat GW are three topical (podophyllin, imiquimod topical, trichloroacetic acid TCA) and three surgical (cryotherapy, electro surgery, and surgical excision). Table 1 shows the estimated cost for each treatment in a single session and the distribution among categories of resource input. Among treatment options, the most expensive was the surgical excision 24USD (95\%CI 12, 57), and the cheapest was TCA with a cost per session of 11USD $(95 \%$ CI 6,18$)$. For all treatment options, the category representing the largest share was human resources, whose cost persession accounted for 70-95\%. The second most important category is disposable materials varying from 1 to $21 \%$ of the total cost per session. This included all goods that are used just once and then disposed of. Supplemental Material contains all costing data used to make these estimations.

Across all treatments, on average, a new case received 2.5 (min: 1, max: 4) sessions of treatment, while a resistant case received 3.4 (min: 1, max: 6). For recurrent cases, the average number of episodes in a year is 1.7 for males and 1.6 for females. Using this information, we estimated the annual average cost per treatment. The most expensive treatment was cryotherapy at 78USD per patient, followed by podophyllin at 58USD, and electrosurgery at 55USD. In contrast, surgical excision was the cheapest treatment at 36USD per patient. (Table 2) For detailed information on the distribution of probabilities across all compartments, please refer to Supplemental material.

After estimating the probabilities for all possible combinations, podophyllin was the most frequently chosen treatment (40\%), followed by electrosurgery (20\%), cryotherapy (17\%), TCA (16\%), imiquimod (5\%), and finally surgical excision (1\%). (Table 2 ) Fig. 2 shows the distribution of treatment choice within physician specialty and type of case. While there is a lot of variability across physicians' specialty, we observe some patterns. For instance, there was a preference for podophyllin by general practitioners which represents the biggest proportion of cases, and dermatologists preferred cryotherapy in any circumstance.

We estimated the average treatment cost in 59.9USD. From the Monte Carlo simulation we estimate the 95\% credibility interval in 45.5 to 77.6 USD. The distribution of the simulations behaves as normal with skewness 0.3 and Kurtosis 3.1. Considering the distribution of cases across gender in the sample, we estimated the annual average cost of treating a male in 61.3USD and a female in 58.9USD. 
Table 1 Cost for each treatment in a single session, by categories of cost

\begin{tabular}{|c|c|c|c|c|c|c|c|}
\hline & $\begin{array}{l}\text { Diagnosis } \\
\text { Appointment }\end{array}$ & Podophyllin & Imiquimod & TCA & Cryotherapy & $\begin{array}{l}\text { Electro } \\
\text { Surgery }\end{array}$ & $\begin{array}{l}\text { Surgical } \\
\text { Excision }\end{array}$ \\
\hline $\begin{array}{l}\text { Cost per session } \\
\text { (USD) }\end{array}$ & $6.04(2.5,11.8)$ & $\begin{array}{l}12.08(7.4, \\
19.3)\end{array}$ & $\begin{array}{l}10.94(6.2 \\
18.3)\end{array}$ & $\begin{array}{l}10.84(6.1, \\
18.2)\end{array}$ & $\begin{array}{l}15.4(8.1, \\
26.8)\end{array}$ & $\begin{array}{l}17.44(9.4, \\
29.3)\end{array}$ & $\begin{array}{l}24.59(12.3, \\
57.6)\end{array}$ \\
\hline \multicolumn{8}{|l|}{$\begin{array}{l}\text { Category of cost } \\
\text { (USD) }\end{array}$} \\
\hline Human Resources & $6.03(2.4,11.8)$ & $9.21(4.5,16.7)$ & $9.21(4.5,16.7)$ & $9.21(4.5,16.7)$ & $\begin{array}{l}13.39(6.2 \\
24.7)\end{array}$ & $13.39(6.2,24.7)$ & $13.86(6.2,26.4)$ \\
\hline Infrastructure & $0.08(0.08,0.08)$ & $0.09(0.09,0.09)$ & $0.09(0.09,0.09)$ & $0.09(0.09,0.09)$ & $\begin{array}{l}0.28(0.27 \\
0.29)\end{array}$ & $0.7(0.69,0.71)$ & $0.44(0.43,0.44)$ \\
\hline Equipment & - & - & - & - & $0.52(0.4,0.7)$ & $1.08(0.01,6.5)$ & - \\
\hline Drugs & - & $1.06(1.06,1.06)$ & $1.44(1.44,1.44)$ & $0.86(0.86,0.86)$ & - & - & $0.96(0.4,1.86)$ \\
\hline Medical instruments & - & - & - & - & - & $0.19(0.18,0.19)$ & $0.69(0.68,0.7)$ \\
\hline Disposable Materials & $0.05(0,0.25)$ & $2.01(1.91,2.28)$ & $0.46(0.26,0.79)$ & $0.93(0.73,1.29)$ & $\begin{array}{l}1.47(0.69, \\
4.82)\end{array}$ & $2.3(0.46,6.82)$ & $9.23(2.04,40.58)$ \\
\hline Water and Electricity & $0.07(0.07,0.07)$ & $0.08(0.08,0.08)$ & $0.08(0.08,0.08)$ & $0.08(0.08,0.08)$ & $\begin{array}{l}0.22(0.22 \\
0.22)\end{array}$ & $0.32(0.32,0.32)$ & $0.19(0.19,0.19)$ \\
\hline
\end{tabular}

USD: United States Dollars; TCA: trichloroacetic acid

The "cost per session" row represent the cost in which the payer incurs every time a physician applies a given treatment. Usually, each treatment is applied more than once depending on the physician's assessment, who considers type of case (new, recurrent, or resistant), and treatment characteristics

Cells marked with "-" indicates that the treatment did not employ those resources

Given the size of the population of the prevalence, we estimate 333,709 annual cases of GW among males and 85,811 among females. Thus, the estimated COI is 25.1 million USD, with a feasible range of 16.9 to 36.5 million USD. Given that the estimated prevalence of GW in males is 3.9 higher than in females [6]. Considering this, the estimated COI for females is 5.1USD million, while the estimated COI for males is 20 million.

\section{Discussion}

This is the first study to estimate the economic burden of treating GW in Peru and one the few in Latin America. Our study leverages information from multiple sources to estimate the cost of several techniques to treat GW, and the associated annual COI for Peruvian healthcare sector. Our statistical approach explicitly incorporates the key factors that determined which treatments are used under what conditions via the assessment of usage probabilities, as well as the uncertainty of the costing data.

We found that human resources account for 70-95\% of the cost per treatment. While these values might look surprising, they are a consequence of the use of diagnosis and treatment techniques that are more intensive in time from healthcare workers than in equipment or other resources. In the selection and implementation of the methods for this study, we accounted for the known issues related to attribution of shared costs [29], that can lead, among others, to overestimation of human resources. We followed several procedures to ensure an

Table 2 Average number of sessions, final cost, and probability of usage for each treatment

\begin{tabular}{lllll}
\hline \multicolumn{5}{c}{ Average Sessions per treatment } \\
\hline \\
Podophyllin & $3.2(2.5,3.7)$ & $4.0(4.0,4.0)$ & 58.6 & Probability of treatment usage \\
Imiquimod & $3.0(2.5,4.0)$ & $2.7(2.4,3)$ & 46.5 & $39.6 \%$ \\
Trichloroacetic Acid & $2.5(1.6,3.3)$ & $5.3(2.0,8.0)$ & 52.7 & $5.3 \%$ \\
Cryotherapy & $3.4(2.8,4.0)$ & $5.1(3.0,6.2)$ & 78.2 & $16.4 \%$ \\
Electro Surgery & $2.0(1.1,4.0)$ & $2.1(2.0,2.3)$ & 55.5 & $17.4 \%$ \\
Surgical Excision & $1.0(1.0,1.0)$ & $1.0(1.0,1.0)$ & 36.1 & $20.3 \%$ \\
\hline
\end{tabular}

USD: United States Dollars

"Average sessions per treatment" indicates the number of sessions until episode resolution. "Probability of treatment usage" column shows the proportions of cases in which each treatment was used. "Annual average cost per treatment" includes cost of diagnosis and control sessions, information of number of sessions per treatment, and proportion of recurrent cases treated with each technique

This table presents summary data. Hence, the sum-product of the last two columns will differ from the reported annual average cost of treatment per person (59.9USD) 


\section{(A) FEMALE PATIENTS}

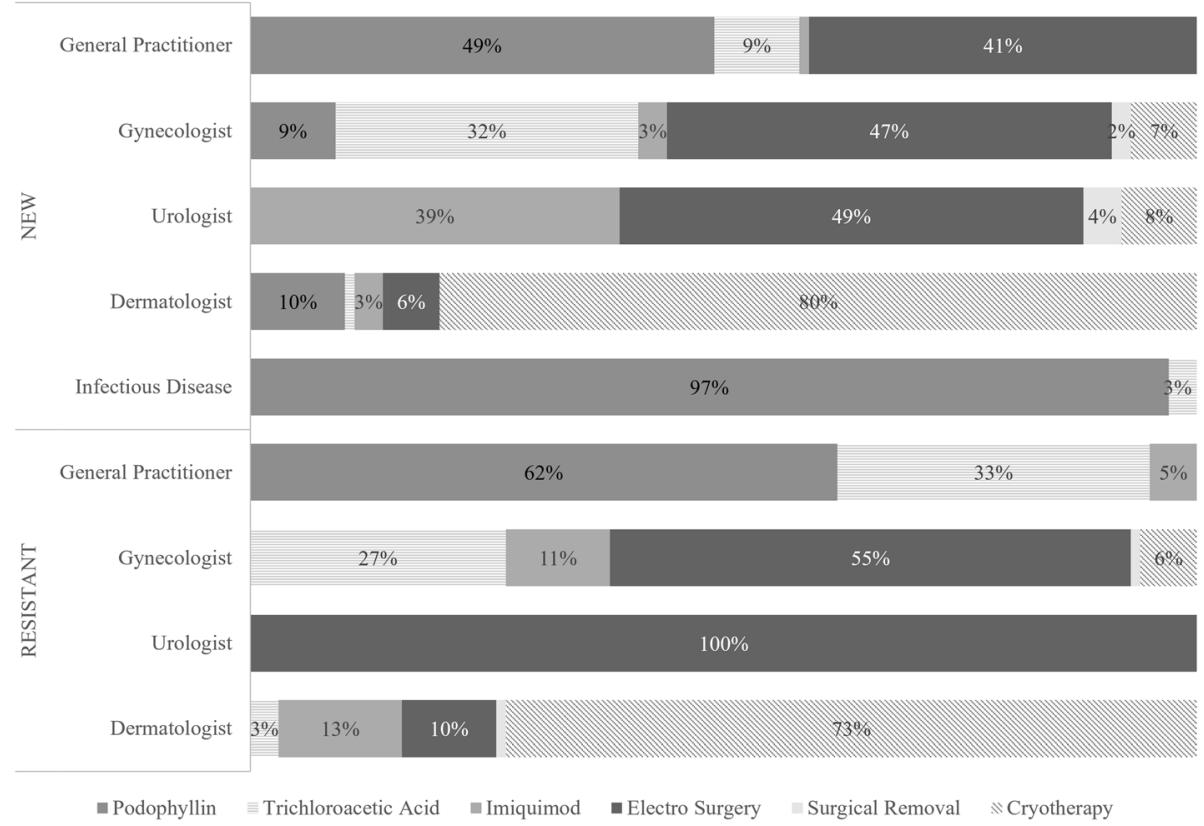

(B) MALE PATIENTS

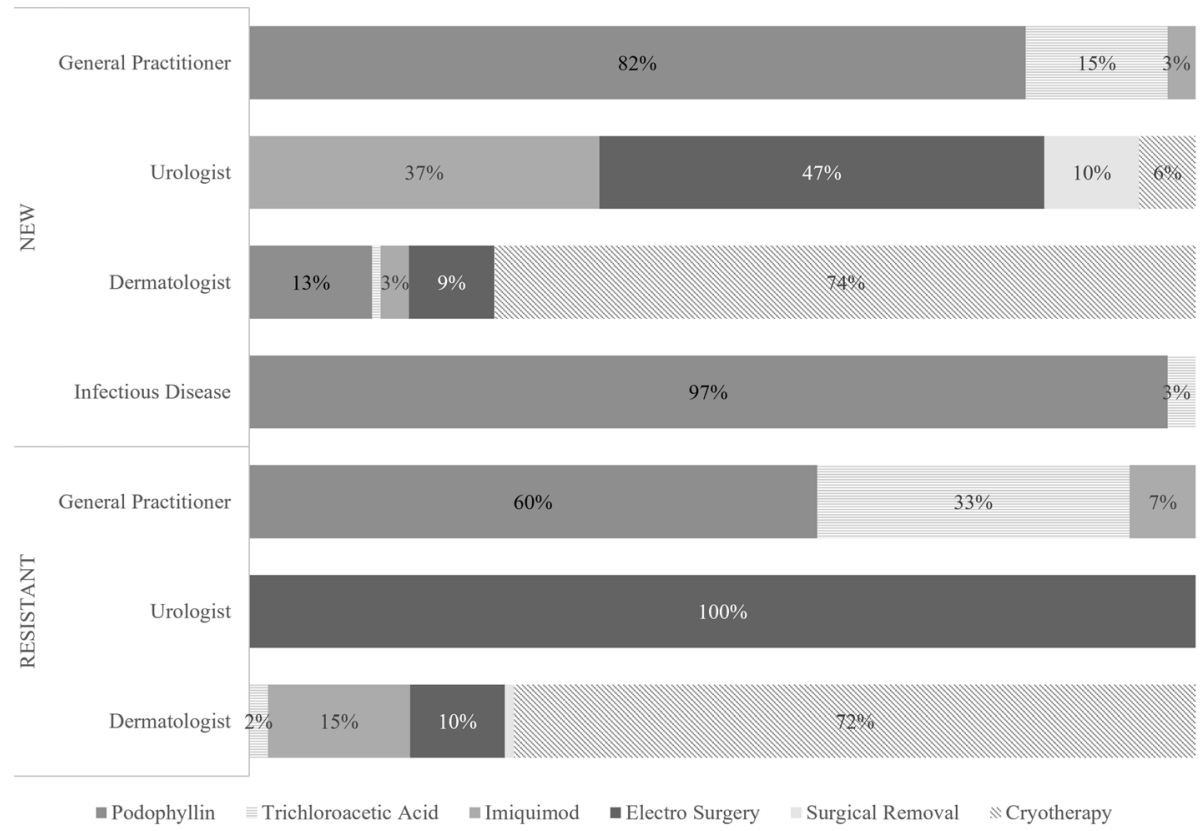

Fig. 2 Distribution of treatment preferences by type of case, physicians' specialty, and gender of the patient. Upper panel (A) corresponds to female patients, and lower panel (B), to female patients. Sections with no label represent $1 \%$

accurate estimation of costs. First, the attribution of healthcare worker by activity was based on a validated flow map. Second, we selected healthcare workers whose activities would less likely overlap to prevent mismatching. Third, the costs estimation was based on governmental data and cleaned from outliers.
Our estimation of 25.1USD million for the COI of GW represents the total expenditures that the Peruvian $\mathrm{MoH}$ would face in diagnoses and treatment of GW in a year. There are few caveats that are important to highlight regarding this estimation. First, the prevalence used was based on formal care; it does not 
include self-treated cases and the cost in which these patients incur are not considered in our estimation of the COI.

Second, per the structure of the Peruvian heath system, only holders of the SIS are eligible to be treated by the $\mathrm{MoH}$ [16]. An important proportion of people with no insurance would seek and receive treatment in the $\mathrm{MoH}$ because it is cheaper than other providers. However, they would need to pay out-ofpocket for all services received. Given the demand size and associated negotiation power, the $\mathrm{MoH}$ prices are lower than other providers, making our COI estimate rather conservative of the total cost of treating GW in the public sector. On the other hand, stock-outs in $\mathrm{MoH}$ operated-facilities and other conditions have been associated with out-of-pocket expenditures in SIS-holders [30] which creates an opposite effect over the COI as some of the $\mathrm{MoH}$ costs could be transferred to individuals.

Third, our analysis implicitly assumes that all patients with detected GW would receive one of the six studied treatment options. According to Garcia et al [6], the proportion of cases that are left untreated are $0.16 \%$ for females and $0.17 \%$ for males. Considering the small number of cases that do not receive treatment once are detected, we did not impose any correction on the prevalence to estimate the COI. On the other hand, in both, Garcia et al. study and our in-depth interviews, the six treatments we analyzed here were the most frequently used ones. Although other treatments were reported, such as interferon or fluorouracil, the proportion of usage was very small and out of the scope of our priorities. We do not have evidence that the inclusion of these treatments would importantly change our results, especially considering the small variability across the cost per session of topical treatments.

Despite these caveats, the estimated COI represent an important amount of money. According to the Peruvian Ministry of Economy and Finance [31], in 2019 the budget for individual health, which includes all actions that aim to treat and rehabilitate people, was around 5.2 billion USD (15.6 billion PEN; the total budget for the $\mathrm{MoH}$ was 20.9 billion PEN), equivalent to 145 USD per capita. Thus, the cost to diagnose and treat GW, as conservative as it is and without considering out-ofpocket expenditures, represents $0.16 \%$ of the total institutional budget. Further, the average per person cost of $\mathrm{GW}$, represents over a third of the per capita value destined to individual health.

Few studies in Latin America have estimated the cost of diagnosis and treatment of GW. For ease of comparison across countries we converted our estimates into international dollars (intl.D) using the purchase parity pawer (PPP) factor published by the World Bank [32]. Considering a PPP factor of 1.74, we estimate the annual average cost of treatment per person in 104.2 intl.D (95\%CI 79.2, 135), and the COI in 43.7intl.D million (uncertainty interval 29.4, 63.5).

An Ecuadorian study used a societal perspective using expert consultation to determine clinical practices. They found that the average cost of treatment varies from 205.4 to 251.7intl.D (PPP factor 0.52), depending on the treatment used [14]. Our results cannot be compared to these results because the authors used a societal perspective, which includes a broader range of costs than to our analysis and includes private practices. Our study was based on the payer's perspective and only from public facilities which tend to be cheaper than private options.

In Mexico, the average cost for diagnosis and treatment of GW was found to be 1,326.8 1,418.5intl.D (PPP factor of 9.15) for men and women, respectively [15]. This study used the healthcare system perspective, and the information was obtained through specialists' interviews. Our estimates are lower than these results, due to the cost of a diagnosis. According to Garcia et al [6]. the diagnosis in Peruvian facilities is made using visual inspection in more than $95 \%$ of the cases; a very cheap technique for which the diagnosis visit is 10.4intl.D. In the Mexican study, consulted physicians reported using laboratory test to diagnose GW. Hence, the average diagnosis appointment alone was 803.4intl.D.

$\mathrm{GW}$ is a vaccine-preventable disease and therefore the costs associated to its diagnosis and treatment can be mitigated [33, 34]. In the United States, quadrivalent vaccine was introduced for females in 2006, and subsequently to males in 2009 [35, 36]. Although the vaccine achieves its highest efficacy in HPV non-exposed individuals (i.e. before sexual initiation, usually younger than 13 years old), the vaccine has been recommended for everybody up to 26 years of age [37]. As a result, there has been a reduction of $0.8 \%$ of genital warts between 2007 and 2014 [38, 39]. Australia is probably an even better example. The country was the first to introduce the quadrivalent HPV vaccine implemented through a national program, targeting girls aged 12 and 13 years, with an additional two catch-up campaigns from 2007 to 2009 targeting women up to 26 years old [40]. In 4 years, the proportion of women under 21 years old diagnosed with GW was reduced from $11.5 \%$ to 2007 to $0.85 \%$ in 2011. Similar declines were observed in men under 21 years of age and men and women of 21 to 30 years old [41, 42].

Under the current immunization scheme, only girls are eligible for the quadrivalent HPV vaccine [19]. However, there is evidence that vaccinating boys could also be beneficial at the individual level, by 
reducing incidence of associated cancers and GW, and at the community level, by reducing the spread of the HPV $[43,44]$. Considering the high concentration of GW cases in males [6] and the estimated higher cost of providing them care, a gender-neutral HPV vaccination approach could potentially save millions of dollars by preventing GW in Peru and improve health outcomes for both males and females [45]. Further, according to the pricelist of the Pan American Health Association (PAHO) the cost for the two-dose quadrivalent HPV-vaccine is 19.9 USD, almost a third of the average cost of treating a GW. Although a study would need to determine how many GW infections the quadrivalent vaccine can prevent in Peru under specific uptake scenarios and target population, two studies in Latin America have found that it can significantly reduce the incidence of $\mathrm{GW}$ in up to $80 \%[46,47]$.

This study was not without limitations. First, we did not collect costs for other healthcare providers besides the $\mathrm{MoH}$ and therefore the estimated $\mathrm{COI}$ is a conservative number compared to the true cost of treating $\mathrm{GW}$ bore by the Peruvian healthcare system. Second, this study uses the prevalence values and physicians' reported preferences for treatment presented by Garcia et al [6] and hence subject to the same limitations and potential sources of bias as presented in that study. Third, the probabilities used to estimate the distribution of cases across combinations of patients' and physicians' characteristics were obtained through interviews and hence subject to recollection and social-desirability biases. Nonetheless, the application of our instruments followed best-practices for data collection [48] and we are confident on the accuracy of our results within its limitations.

\section{Conclusions}

To our knowledge, this is the first study that analyzes the economic burden of GW in Peru, and one of the few in Latin America. We used a micro-costing technique with data collection in multiple settings to account for the regional price variability. Our fieldwork collection was supplemented with governmental data, which improve the precision of our estimates. Finally, we explicitly assess uncertainty in our estimates by including confidence intervals and performing a Monte Carlo simulation to estimate credible intervals for the average cost of treatment.

We hope our findings bring attention to the economic consequences of diagnosing and treating GW, and the burden that it represents to the $\mathrm{MoH}$ and the Peruvian Healthcare sector at large and becomes another reason to make the decision of moving forward into genderneutral vaccination.

\section{Supplementary information}

The online version contains supplementary material available at https://doi. org/10.1186/s12913-021-07120-w.

\section{Additional file 1}

Acknowledgements

Jonathan Augurto and Sandra Solis, University Cayetano Heredia, provided excellent assistant with the data collection and cleaning. The authors would like to thank the journal reviewers for their excellent comments.

\section{Authors' contributions}

Concept and Design: ES, PG, CC; Acquisition of Data: ES; Analysis and interpretation of data: ES, PG, CC, JB; Drafting of the manuscript: ES; Critical revision of the paper: $E S, P G, C C, J B$; Statistical analysis: ES; Obtaining funding: $P G, C C$. All authors have read and approved the manuscript.

\section{Funding}

Financial support for this study was provided Merck \& Co., Inc., Kenilworth, NJ, USA.

\section{Availability of data and materials}

The authors have made available all data and materials in the Supplemental file.

\section{Declarations}

Ethics approval and consent to participate

The protocol and instruments were reviewed and approved by the IRB of the Universidad Peruana Cayetano Heredia (\# 65616). All protocols are carried out in accordance with relevant guidelines and regulations. Participants were aware of the study and understood the benefits and risks involved. Informed consent was obtained from all participants.

\section{Consent for publication}

Not applicable.

\section{Competing interests}

Merck \& Co., Inc., produces Gardasil 4-valent HPV vaccine however, the funder had no role in the design and conduct of the study; collection, management, analysis, and interpretation of the data; preparation, review, or approval of the manuscript; and decision to submit the manuscript for publication. The authors have no competing interest to declare.

\section{Author details}

${ }^{1}$ Epidemiology, STD and HIV Unit, School of Public Health and Administration, Universidad Peruana Cayetano Heredia, Lima, Peru. ${ }^{2}$ The Comparative Health Outcomes, Policy, and Economics (CHOICE) Institute, University of Washington, Seattle, Washington, USA. ${ }^{3}$ Department of Global Health, School of Public Health, University of Washington, Seattle, Washington, USA.

Received: 1 June 2021 Accepted: 1 October 2021

Published online: 14 October 2021

\section{References}

1. Patel $H$, Wagner $M$, Singhal $P$, Kothari S. Systematic review of the incidence and prevalence of genital warts. BMC Infect Dis. 2013 Jan 25;13(1):39.

2. Garland SM, Steben M, Sings HL, James M, Lu S, Railkar R, et al. Natural history of genital warts: analysis of the placebo arm of 2 randomized phase III trials of a quadrivalent human papillomavirus (types $6,11,16$, and 18) vaccine. J Infect Dis. 2009 Mar 15:199(6):805-14

3. McQuillan G, Kruszon-Moran D, Markowitz LE, Unger ER, Paulose-Ram R. Prevalence of HPV in Adults Aged 18-69: United States, 2011-2014. NCHS Data Brief. 2017 Apr;(280):1-8.

4. Satterwhite $\mathrm{CL}$, Torrone $\mathrm{E}$, Meites E, Dunne EF, Mahajan R, Ocfemia MCB, et al. Sexually transmitted infections among US women and men: prevalence and incidence estimates, 2008. Sex Transm Dis. 2013 Mar;40(3): 187-93. 
5. Lynde C, Vender R, Bourcier M, Bhatia N. Clinical features of external genital warts. J Cutan Med Surg. 2013 Dec;17 Suppl 2:S55-60.

6. García PJ, Carcamo CP, Valderrama M, La Rosa S, James C, Gutiérrez R, et al. Burden of genital warts in Peru: an observational study. Int J STD AIDS. 2019 Mar;30(3):264-74.

7. Kilciler M, Bedir S, Erdemir F, Coban H, Erten K, Ors O, et al. Condylomata acuminata of external urethral meatus causing infravesical obstruction. Int Urol Nephrol. 2007;39(1):107-9.

8. Chae JY, Bae JH, Yoon CY, Park HS, Moon DG, Lee JG, et al. Female Urethral Condyloma Causing Bladder Outlet Obstruction. Int Neurourol J. 2014 Mar; 18(1):42-4.

9. Workowski KA, Bolan G. Sexually Transmitted Diseases Treatment Guidelines, 2015 [Internet]. Centers for Disease Control and Prevention - CDC; 2015. Report No:: 64(RR2); 1-137. Available from: https://www.cdc.gov/mmwr/ preview/mmwrhtml/rr6403a1.htm

10. Woodhall SC, Jit M, Soldan K, Kinghorn G, Gilson R, Nathan M, et al. The impact of genital warts: loss of quality of life and cost of treatment in eight sexual health clinics in the UK. Sex Transm Infect. 2011 Oct;87(6):458-63.

11. Park YJ, Kim JM, Lee BR, Kim TH, Lee EG. Annual prevalence and economic burden of genital warts in Korea: Health Insurance Review and Assessment (HIRA) service data from 2007 to 2015. Epidemiol Infect. 2018;146(2):177-86.

12. Coles V a. H, Chapman R, Lanitis T, Carroll SM. The costs of managing genital warts in the UK by devolved nation: England, Scotland, Wales and Northern Ireland. Int J STD AIDS. 2016 Jan;27(1):51-7.

13. Domenech-Viñolas $M$, León-Maldonado L, Ramírez-Palacios P, Flores YN, Granados-García V, Brown B, et al. Incidence, psychosocial burden, and economic impact of genital warts in Mexico. Salud Publica Mex. 2018 Nov; 60(6):624-32.

14. Roldos M, Bustamante V. Consensus of Clinical Practices And Associated Costs To Diagnose And Treat Genital Warts Caused By Human Papilloma Virus (Hpv) In Ecuador: Results From A Panel Of Experts. Value Health. 2015 Nov 1;18:A833.

15. Reyes-Lopez A, Pérez Bolde-Villarreal C, Pastor-Martinez V. Uso de recursos y costos asociados al diagnóstico y tratamiento de las verrugas genitales en instituciones públicas de salud en México. Rev Mex Urol. 2015 Mar 1;75:72-81.

16. Alcalde-Rabanal JE, Lazo-González O, Nigenda G. The health system of Peru]. Salud Publica Mex. 2011;53 Suppl 2:s243-254.

17. Durand-Carrion D. [Population with any kind of health insurance] [Internet]. Lima: Instituto Nacional de Estadística e Informática - INEl; 2018 Nov. Available from: https://www.inei.gob.pe/media/MenuRecursivo/publica ciones_digitales/Est/Lib1587/libro01.pdf

18. Murillo R, Almonte M, Pereira A, Ferrer E, Gamboa OA, Jerónimo J, et al. Cervical cancer screening programs in Latin America and the Caribbean. Vaccine. 2008 Aug 19;26 Suppl 11:L37-48.

19. MINSA. Resolución Ministerial 651-2016-MINSA. Ministerio de Salud - MINSA: 2016 Agosto.

20. Garrison LP, Pauly MV, Willke RJ, Neumann PJ. An Overview of Value, Perspective, and Decision Context-A Health Economics Approach: An ISPOR Special Task Force Report [2]. Value Health. 2018 Feb;21 (2):124-30.

21. Akobundu E, Ju J, Blatt L, Mullins CD. Cost-of-Illness Studies. PharmacoEconomics. 2006 Sep 1;24(9):869-90.

22. Jo C. Cost-of-illness studies: concepts, scopes, and methods. Clin Mol Hepatol. 2014 Dec;20(4):327-37.

23. DGSP, DAIS. [National Guidelines for integral care of Sexual and reproductive health] [Internet]. Lima, Peru: Ministry of Health; 2004. Available from: http://bvs.minsa.gob.pe/local/dgsp/63_guiasnac.pdf

24. Lau F. Chapter 14 Methods for eHealth Economic Evaluation Studies [Internet]. Handbook of eHealth Evaluation: An Evidence-based Approach [Internet]. University of Victoria; 2017 [cited 2021 Jun 28]. Available from: https://www.ncbi.nlm.nih.gov/books/NBK481607/

25. Drummond MF, Sculpher MJ, Claxton K, Stoddart GL, Torrance GW. Methods for the Economic Evaluation of Health Care Programmes [Internet]. Oxford, UNITED KINGDOM: Oxford University Press; 2015 [cited 2021 May 31]. Available from: http://ebookcentral.proquest.com/lib/washington/deta il.action?doclD=4605509

26. Briggs A. Probabilistic Analysis of Cost-Effectiveness Models: Statistical Representation of Parameter Uncertainty. Value Health. 2005;8(1):1-2.

27. Briggs $A H$, Weinstein MC, Fenwick EAL, Karnon J, Sculpher MJ, Paltiel AD, et al. Model parameter estimation and uncertainty analysis: a report of the ISPOR-SMDM Modeling Good Research Practices Task Force Working Group6. Med Decis Mak Int J Soc Med Decis Mak. 2012 Oct;32(5):722-32.
28. INEI. [Total population at June 30 of every year, by sex and age groups] [Internet]. Instituto Nacional de estadistica e Informatica - INEl; ND. Available from: https://www.inei.gob.pe/estadisticas/indice-tematico/poblacion-yvivienda/

29. Rosen AB, Aizcorbe A, Highfill T, Chernew ME, Liebman E, Ghosh K, et al. Attribution of Health Care Costs to Diseases: Does the Method Matter? In: Measuring and Modeling Health Care Costs [Internet]. University of Chicago Press; 2016 [cited 2021 Aug 2]. p. 173-210. Available from: https://www. nber.org/books-and-chapters/measuring-and-modeling-health-care-costs/a ttribution-health-care-costs-diseases-does-method-matter

30. Pavone MP, Sánchez EJ. Determinants of out-of-pocket spending on health among the poor population served by public health services in Peru, 20102014. Rev Panam Salud Pública. 2018 Oct 18:42:e20.

31. Peruvian Ministry of Economic and Finance. [Friendly Search (Monthly). Public Expenditure Execution Search] [Internet]. Economic Transparency. [cited 2020 Jan 15]. Available from: http://apps5.mineco.gob.pe/transpa rencia/mensual/

32. The World Bank. PPP conversion factor [Internet]. [cited 2021 Apr 5]. Available from: https://data.worldbank.org/indicator/PA.NUS.PPP

33. Garland SM, Hernandez-Avila M, Wheeler CM, Perez G, Harper DM, Leodolter $\mathrm{S}$, et al. Quadrivalent vaccine against human papillomavirus to prevent anogenital diseases. N Engl J Med. 2007 May 10;356(19):1928-43.

34. FUTURE II Study Group. Quadrivalent vaccine against human papillomavirus to prevent high-grade cervical lesions. N Engl J Med. 2007 May 10;356(19): 1915-27.

35. Centers for Disease Control and Prevention (CDC). FDA licensure of quadrivalent human papillomavirus vaccine (HPV4, Gardasil) for use in males and guidance from the Advisory Committee on Immunization Practices (ACIP). MMWR Morb Mortal Wkly Rep. 2010 May 28;59(20):630-2.

36. Markowitz LE, Dunne EF, Saraiya M, Lawson HW, Chesson H, Unger ER, et al. Quadrivalent Human Papillomavirus Vaccine: Recommendations of the Advisory Committee on Immunization Practices (ACIP). MMWR Recomm Rep Morb Mortal Wkly Rep Recomm Rep. 2007 Mar 23;56(RR-2):1-24.

37. Meites E. Human Papillomavirus Vaccination for Adults: Updated Recommendations of the Advisory Committee on Immunization Practices. MMWR Morb Mortal Wkly Rep [Internet]. 2019 [cited 2019 Oct 25];68. Available from: https://www.cdc.gov/mmwr/volumes/68/wr/ mm6832a3.htm

38. Oliver SE, Unger ER, Lewis R, McDaniel D, Gargano JW, Steinau M, et al. Prevalence of Human Papillomavirus Among Females After Vaccine Introduction-National Health and Nutrition Examination Survey, United States, 2003-2014. J Infect Dis. 2017 Sep 1;216(5):594-603.

39. Markowitz LE, Liu G, Hariri S, Steinau M, Dunne EF, Unger ER. Prevalence of HPV After Introduction of the Vaccination Program in the United States. Pediatrics. 2016 Mar 1;137(3):e20151968.

40. Garland SM, Skinner SR, Brotherton JML. Adolescent and young adult HPV vaccination in Australia: Achievements and challenges. Prev Med. 2011 Oct 1;:53:S29-35.

41. Ali H, Donovan B, Wand H, Read TRH, Regan DG, Grulich AE, et al. Genital warts in young Australians five years into national human papillomavirus vaccination programme: national surveillance data. BMJ. 2013 Apr 18;346:f2032.

42. Patel C, Brotherton JM, Pillsbury A, Jayasinghe S, Donovan B, Macartney $K$, et al. The impact of 10 years of human papillomavirus (HPV) vaccination in Australia: what additional disease burden will a nonavalent vaccine prevent? Eurosurveillance [Internet]. 2018 Oct 11 [cited 2019 Oct 25];23(41). Available from: https://www.ncbi.nlm.nih.gov/pmc/articles/PMC6194907/

43. Bogaards JA, Wallinga J, Brakenhoff RH, Meijer CJLM, Berkhof J. Direct benefit of vaccinating boys along with girls against oncogenic human papillomavirus: bayesian evidence synthesis. BMJ. 2015 May 12;350:h2016.

44. Elfström KM, Lazzarato F, Franceschi S, Dillner J, Baussano I. Human Papillomavirus Vaccination of Boys and Extended Catch-up Vaccination: Effects on the Resilience of Programs. J Infect Dis. 2016 Jan 15;213(2): 199-205.

45. Hintze JM, O'Neill JP. Strengthening the case for gender-neutral and the nonavalent HPV vaccine. Eur Arch Oto-Rhino-Laryngol Off J Eur Fed OtoRhino-Laryngol Soc EUFOS Affil Ger Soc Oto-Rhino-Laryngol - Head Neck Surg. 2018 Apr;275(4):857-65.

46. Ortiz AP, Ortiz-Ortiz KJ, Ríos M, Laborde J, Kulkarni A, Pillsbury M, et al. Modelling the effects of quadrivalent Human Papillomavirus (HPV) vaccination in Puerto Rico. PLoS ONE. 2017 Nov 30;12(11):e0184540. 
47. Bardach AE, Garay OU, Calderón M, Pichón-Riviére A, Augustovski F, Martí SG, et al. Health economic evaluation of Human Papillomavirus vaccines in women from Venezuela by a lifetime Markov cohort model. BMC Public Health. 2017 Feb 2;17:152.

48. Frick KD. Micro-Costing Quantity Data Collection Methods. Med Care. 2009 Jul;:47(7 Suppl 1):S76-81.

\section{Publisher's Note}

Springer Nature remains neutral with regard to jurisdictional claims in published maps and institutional affiliations.

Ready to submit your research? Choose BMC and benefit from:

- fast, convenient online submission

- thorough peer review by experienced researchers in your field

- rapid publication on acceptance

- support for research data, including large and complex data types

- gold Open Access which fosters wider collaboration and increased citations

- maximum visibility for your research: over $100 \mathrm{M}$ website views per year

At BMC, research is always in progress.

Learn more biomedcentral.com/submissions 